\title{
DESIGUALDADES NO INTERIOR DAS ESCOLAS: UMA ANÁLISE DA COMPOSIÇÃO SOCIAL DAS TURMAS \\ http://dx.doi.org/10.5902/2318133865270
}

\author{
Tatiana Maria Cruz ${ }^{1}$ \\ Flavia Pereira Xavier² \\ Valéria Cristina de Oliveira ${ }^{3}$
}

\begin{abstract}
Resumo
Neste trabalho analisa-se as desigualdades de composição social das turmas de $5^{\circ}$ ano da rede pública brasileira. Além disso, busca-se verificar se há correspondência entre a composição das turmas e os critérios de enturmação declarados pelos diretores. A composição social de cada uma das turmas foi calculada a partir do percentual de alunos negros, do sexo feminino, reprovados, de baixo nível socioeconômico e não proficientes em Leitura e Matemática. O Índice de Theil-L descreve a desigualdade entre as turmas quanto à sua composição e compara aos critérios para organização das turmas. Constatamos que há um descompasso entre a distribuição desigual dos alunos e a percepção dos diretores, mesmo quando afirmaram utilizar critérios de enturmação baseados na heterogeneidade.

Palavras-chave: alocação dos alunos em turmas; composição social das turmas; desigualdades escolares.
\end{abstract}

\section{INEQUITY INSIDE SCHOOLS: AN ANALYSIS OF CLASSES SOCIAL COMPOSITION}

\begin{abstract}
This article analyzes the social composition of fifth grade classes in Brazilian public schools. Besides, investigates the correspondence between class social composition and the within-class criteria of grouping. We consider the social composition of classes as the percentage of students who failed in the past, who are black, female, low socioeconomic level or low achievement in reading and mathematics tests. Then, we use the Theil-L Index to describe at first the inequality between classes considering their social composition and, on the other hand, to compare it to the within-class criteria of grouping declared by the principal. As a result, we observe that there is a mismatch between the unequal distribution of students among classes and the perception of principals, even when they stated that were applied a heterogeneous grouping criteria.

Keywords: class's allocation; social composition of classes; school inequalities.
\end{abstract}

\footnotetext{
1 Universidade Federal de Minas Gerais, Brasil. E-mail: taticruz2813@ufmg.br.

2 Universidade Federal de Minas Gerais, Brasil. E-mail: flaviapx@ufmg.br.

3 Universidade Federal de Minas Gerais, Brasil. E-mail: valcrisoli@ufmg.br. 


\section{Introdução}

Neste artigo discute-se um dos fatores da escola que podem contribuir para compreensão das desigualdades entre os estudantes e seus resultados: 0 processo de formação de turmas. Para isso analisamos a composição das turmas do $5^{\circ}$ ano do ensino fundamental da rede pública brasileira e o modo como ela se associa aos principais marcadores de desigualdades - sexo, cor/raça, nível socioeconômico, trajetória e desempenho escolar - e ao critério de enturmação adotado na escola, conforme o informado pelos diretores.

A Sociologia da Educação, desde a década de 1950, tem mostrado como a estrutura escolar se articula a desigualdades de oportunidades desiguais e estruturas educacionais (Costa; Koslinsky, 2008), sendo as desigualdades escolares tema recorrente na literatura internacional e nacional (Dubet, 2004; Duru-Bellat, 2005; Ribeiro, 2006; Alves; Soares, 2007; Alves; Soares; Xavier, 2016).

As discussões sobre essas temáticas se desenvolveram, em grande medida, como resposta à publicação, na década de 1960, de dois estudos demandados pelos governos dos Estados Unidos e Inglaterra, respectivamente, conhecidos como Relatório Coleman (Coleman, 1966) e Relatório Plowden (Plowden, 1967). As duas pesquisas investigaram os condicionantes da qualidade e as raízes das lacunas entre alunos em diferentes estabelecimentos de ensino, mostrando como a escola tinha pequena influência no desempenho, face à origem social e econômica dos estudantes e de suas famílias.

Os resultados do Relatório Coleman evidenciaram que o background familiar afetava mais que a escola o progresso acadêmico dos estudantes, em outras palavras, as fontes das disparidades de oportunidades educacionais encontravam-se, em primeiro lugar, nas famílias e nas influências culturais que a cercam e, depois, na ineficácia das escolas em combater essas diferenças e contrastes (Brooke; Soares, 2008).

Os resultados do Relatório Plowden corroboram os resultados de Coleman na medida em que se constatou que a influência e a participação efetiva dos pais na vida escolar dos filhos como, por exemplo, na presença em reuniões escolares ou na ajuda com o dever de casa, contribuíram para o sucesso escolar em Leitura e Matemática. Os dois relatórios reforçaram a noção de que a escola não era fator decisivo para os bons resultados em termos de aprendizado (Brooke; Soares, 2008).

Diante da polêmica causada com a divulgação desses relatórios, surgiram pesquisas que analisaram se os efeitos devidos às escolas eram mesmo tão pequenos, mesmo quando submetidas às diferenças de origem socioeconômica (Sammons; Hillman; Mortimore, 1995). Tais estudos, conhecidos como pesquisas sobre efeito-escola ou eficácia escolar, colocaram foco na análise dos processos intraescolares, buscando entender o fenômeno a partir da comparação entre as escolas.

As pesquisas no campo da Sociologia da Educação, além de considerarem as questões de oportunidades educacionais desiguais, ponderam o efeito da origem social dos estudantes nesse contexto (Couri, 2010; Dubet, 2012; Alves; Soares, 2013). Para os autores da área, além de se buscar compreender o que ocorre antes da escolarização, é importante examinar os processos que acontecem durante a escolarização, pois assumem que a escola pode reforçar ou mitigar essas desigualdades. Nesse sentido, o modo como as escolas planejam e organizam suas turmas pode ser considerado um dos fatores intraescolares a atenuar ou acentuar as disparidades escolares. De tal maneira a 
organização das turmas não é uma preocupação apenas pedagógica, mas também sociológica e orienta a nossa hipótese de que os diversos marcadores sociais e escolares agem, mesmo que implicitamente, como critérios de enturmação.

\section{O processo de formação de turmas e desigualdades escolares}

O ensino fundamental integra a educação básica, junto com a educação infantil e o ensino médio. É dever do Estado garantir o ensino fundamental de caráter obrigatório, gratuito e comprometer-se com a progressiva extensão de obrigatoriedade e gratuidade ao ensino médio (Brasil, 1996). O Plano Nacional de Educação, decênio 2001-2010, estabeleceu como uma das suas metas "ampliar para nove anos a duração do ensino fundamental obrigatório com início aos seis anos de idade, à medida que for sendo universalizado o atendimento na faixa etária de 7 a 14 anos" (Brasil, 2001). O aumento do número de anos do ensino fundamental teve como objetivo oferecer maiores oportunidades de aprendizagem às crianças, sem perder de vista um ensino de qualidade. Entretanto, somente essa ampliação dos anos não garantiu o aprendizado adequado dos alunos, como apontam diversas pesquisas (Soares, 2004; Alves; Soares, 2013; Alves; Soares; Xavier, 2016). Além disso os resultados das avaliações externas, como a Prova Brasil, mostram que essa etapa de ensino continua sendo marcada por desigualdades, exclusão e seletividade, o que impacta, tanto a qualidade, quanto a equidade.

Alves, Soares e Xavier (2016) ressaltam que, apesar de não haver um consenso ou universalidade sobre os conceitos de qualidade e equidade, a primeira pode ser definida como o acesso, a progressão, a permanência e a trajetória regular do estudante assegurados pelo aprendizado permanente. A equidade está relacionada a um sistema escolar mais justo, em que mesmo com as desigualdades sociais entre os indivíduos há uma busca por políticas que tentem equilibrar tais desvantagens.

Para Dubet (2019) a democratização do acesso ao ensino "não reduziu o impacto da origem social e cultural dos alunos sobre suas performances e suas carreiras escolares" (Dubet, 2019, p. 8) uma vez que, ao analisar os resultados escolares, esses fatores estruturais permanecem como importantes variáveis explicativas. Ao exemplificar o contexto francês observa-se que as diferenças de recursos financeiros e culturais das famílias proporcionam diferentes formas e estratégias de investimento na educação escolar dos filhos, o que também pode ser notado no Brasil, mesmo com as particularidades observadas na comparação entre os sistemas educacionais dos dois países.

Parte-se da ideia de que a desigualdade de aprendizado não pode ser vista de forma individualizada ou na comparação entre alunos, mas entre grupos sociais, pois, apesar de ser observada no nível dos indivíduos, ela alude ao afastamento entre os grupos sociais quanto ao ingresso, à trajetória regular e ao aprendizado (Alves; Soares; Xavier, 2016). Num país como o Brasil, onde a distribuição de renda associa-se a outros marcadores demográficos importantes, gerando desigualdade em um sentido amplo, cor/raça, sexo e NSE são variáveis elementares para se investigarem os resultados escolares. Em vista disso pesquisas e avaliações externas no país e no mundo evidenciam discrepâncias educacionais em termos de aprendizado entre os grupos. 
Num contexto ideal, em situações de equidade, o aprendizado entre os grupos deveria ser similar, entretanto, como isso não ocorre. Há evidências de que variações significativas dos resultados também podem ser observadas na comparação entre escolas, entre tipos de dependência administrativa (Barbosa; Fernandes, 2001) ou dentro do próprio estabelecimento de ensino, o que caracteriza a desigualdade intraescolar (Franco et al., 2007).

Os fatores que influenciam essas desigualdades intraescolares podem ser externos ou internos à escola. Os fatores externos estão ligados aos alunos e suas características, como cor/raça, sexo, NSE, questões familiares, etc. Os fatores internos estão relacionados às estruturas escolares, como a organização escolar, administração dos recursos financeiros, entre outros. Sendo assim, os fatores intraescolares se referem às questões da escola que podem fomentar as disparidades entre o desempenho dos estudantes (Barbosa; Fernandes, 2001; Gomes, 2005).

Escolhemos analisar as formas de organização de turmas porque, apesar de também afetar a qualidade do aprendizado, ao contrário do que ocorre com outros fatores de origem socioeconômica, na maior parte das vezes é um processo que compete somente à gestão escolar. Pesquisas mostram que quando o critério utilizado para formação de turmas é homogeneidade quanto à idade, ele não favorece o aprendizado mais equitativo dos estudantes, principalmente se há uma defasagem na idade adequada à série cursada (Barboza, 2006; Leo; Cruz, 2016; Oliveira, 2014).

Tais resultados corroboraram estudos de Alves e Soares (2007) que, ao realizarem uma pesquisa com dados longitudinais, observaram que além de fatores individuais do aluno a formação de turmas por nível de habilidade, que coincide com o nível socioeconômico e a média da defasagem de idade-série das turmas, impacta não somente o desempenho dos alunos, mas inclusive as diferenças nas taxas de progresso observadas durante o estudo (Alves; Soares, 2007). Noutra pesquisa Leo e Cruz (2016) investigaram o vínculo entre a organização de turmas e o aprendizado dos alunos por meio de análise dos questionários contextuais da Prova Brasil de 2013. A intenção das autoras foi identificar como essa organização tinha sido realizada e suas possíveis influências na proficiência média do aluno em Matemática no 9 o ano do ensino fundamental. O resultado indicou que, apesar das redes estaduais e municipais informarem utilizar amplamente o critério de formação das turmas pela homogeneidade quanto à idade, foi nas turmas em que se aplicou o critério de heterogeneidade quanto ao rendimento escolar que as médias das proficiências em Matemática na Prova Brasil foram mais altas (Leo; Cruz, 2016).

Bartholo e Costa (2014) aprofundaram a análise dos padrões de segregação entre e intra escolas de acordo com os turnos escolares e, para isso, utilizaram os dados da rede municipal de educação do Rio de Janeiro de 2004 a 2010. Os autores criaram um índice de segregação que levou em consideração quatro características dos estudantes: condição de pobreza, cor/raça, educação parental e distorção idade-série. Como resultado foi possível afirmar que os alunos são habitualmente combinados com base em seu desempenho acadêmico pregresso, medido por distorção idade-série. Além disso a 
forma que os alunos estão distribuídos ou foram selecionados para os turnos escolares tem impacto nos níveis de segregação. Essa pesquisa chama atenção para o fato de que os turnos podem representar o que eles chamaram de tracking informal, ou seja, mais uma das formas de segregação intraescolar (Bartholo; Costa, 2014).

Contudo, a literatura vem demonstrando o quanto essa forma de organização, seja por alocar maior quantidade de alunos com distorção idade-série numa mesma turma, seja por formar turmas homogêneas quanto à idade, em longo prazo, pode representar um prejuízo às práticas escolares. Quando a instituição escolar, no decorrer dos ciclos ou séries, tende a formar as turmas dessa maneira, há uma tendência crescente de uma influência negativa no aprendizado dos seus estudantes (Alves; Soares, 2007).

\section{Metodologia}

Utilizamos os dados da Prova Brasil do ano de 2017, que faz parte do Sistema de Avaliação da Educação Básica - Saeb4. O Saeb foi criado com o objetivo de avaliar a qualidade do ensino ministrado nas escolas das redes públicas, ou seja, seu objetivo é avaliar o sistema de ensino e não os discentes. Os alunos que participam da avaliação fazem dois testes: um de Língua Portuguesa e outro de Matemática. A proficiência é estimada com base no modelo unidimensional logístico de três parâmetros da Teoria de Resposta ao Item - TRI ${ }^{5}$.

Para a realização deste estudo foram utilizados dois questionários da Prova Brasil: um referente aos alunos do $5^{\circ}$ ano do ensino fundamental que participaram do teste e outro respondido pelo diretor. Neste selecionamos especificamente o item do questionário que perguntou sobre os critérios de organização das turmas utilizados na escola. 0 levantamento no ano de 2017 teve participação de 2.594.335 estudantes e 71.073 escolas. Separamos para a análise apenas as escolas da rede pública municipal e estadual $^{6}$ totalizando 2.193 .577 alunos em 47.808 escolas. $O$ interesse da pesquisa pela rede pública de ensino decorre do fato dessa rede atender mais de $80 \%$ dos estudantes do ensino fundamental, o que engloba alunos de 6 a 14 anos, de acordo com os dados do censo da educação básica?.

A partir dessa extensa base de dados, com representatividade de todo o território nacional, elaboramos um desenho de investigação baseado em duas etapas. A primeira consistiu em elaborar uma medida de composição de turmas segundo os marcadores

\footnotetext{
4 Até a versão realizada em 2017, o Saeb foi composto por três avaliações: Avaliação Nacional da Educação Básica - Aneb -, Avaliação Nacional do Rendimento Escolar - Anresc/Prova Brasil - e Avaliação Nacional da Alfabetização - ANA - e tem como objetivo realizar um diagnóstico da educação básica brasileira e de alguns fatores que possam interferir no desempenho do estudante, fornecendo um indicativo sobre a qualidade do ensino ofertado. Os microdados da avaliação são públicos e disponíveis para download. Para maiores informações: http://sistemasprovabrasil.inep.gov.br.

5 TRI é um conjunto de modelos matemáticos, em que a probabilidade de resposta a um item é modelada como função de proficiência - (habilidade -) do aluno - (variável latente, não observável )- e de parâmetros que expressam certas propriedades dos itens (Klein, 2015).

${ }^{6}$ A rede federal de ensino integra a rede pública, entretanto, para esta pesquisa como esta rede apresenta características diferenciadas - quantidade de escolas, nível de abrangência, processo de seleção etc. - da rede estadual e municipal ela não feaz parte deste trabalho.

7 O Censo da Educação Básica é o principal instrumento de coleta de informações da educação básica e o mais importante levantamento estatístico educacional brasileiro nessa área. Maiores inlnformações: http://portal.inep.gov.br/censo-escolar.

Regae: Rev. Gest. Aval. Educ. Santa Maria

v. 10

n. 19

e65270, p. 1-19

2021
} 
sociodemográficos e escolares selecionados. Assim, foram calculados os percentuais de estudantes pretos e pardos, do sexo feminino, com baixo nível socioeconômico, que já foram reprovados e não proficientes em Leitura e Matemática.

$\mathrm{Na}$ sequência mensuramos o grau de desigualdade das escolas quanto a essas medidas de composição. Nesse intuito o Índice de Theil-L (Theil,1967) foi adotado como indicador sintético de desigualdade que avaliou o grau de concentração de estudantes em situação de maior vulnerabilidade social por escolas. Nesta etapa apenas as escolas com duas ou mais turmas foram selecionadas, permanecendo na análise 26.432 diretores e 2.154.146 alunos distribuídos em 77.455 turmas de 27.491 escolas.

A análise descritiva univariada e bivariada do índice apontou os grupos sociais com maior heterogeneidade nas escolas brasileiras em turmas de $5^{\circ}$ ano do ensino fundamental, além de contrastá-lo ao critério de formação das turmas alegado pelo diretor.

\section{Composição social das turmas: percentuais de matriculados em situação de desvantagem social}

A composição social das turmas é um tema bastante explorado na literatura especializada e tem sido operacionalizado como a agregação de características socioeconômicas e culturais observadas entre os alunos (Barboza, 2006; Costa; Koslinski, 2008; Bartholo; Costa, 2014). Esta também é a estratégia que adotamos.

As medidas de composição foram elaboradas a partir de seis variáveis de características sociodemográficas e escolares dos alunos: cor/ raça, sexo, reprovação, nível socioeconômico e níveis de aprendizado em Leitura e Matemática. O quadro 1 apresenta a descrição das variáveis.

Quadro 1 -

Variáveis utilizadas da Prova Brasil do ano de 2017.

\begin{tabular}{|l|l|l|l|}
\hline \multicolumn{1}{|c|}{ Variável } & \multicolumn{1}{|c|}{ Tipo } & \multicolumn{1}{c|}{ Descrição da variável original } & \multicolumn{1}{c|}{$\begin{array}{c}\text { Medida de } \\
\text { composição da } \\
\text { turma }\end{array}$} \\
\hline Cor ou raça & Categórica & $\begin{array}{l}\text { O Saeb replica as categorias utilizadas } \\
\text { pelo Instituto Brasileiro de Geografia e } \\
\text { Estatística - IBGE: branca, parda, } \\
\text { preta, amarela ou indígena. }\end{array}$ & $\begin{array}{l}\text { Percentual de } \\
\text { estudantes pretos. } \\
\text { Percentual de } \\
\text { estudantes pardos }\end{array}$ \\
\hline Sexo & Categórica & $\begin{array}{l}\text { Esse item possui duas opções de } \\
\text { resposta (masculino ou feminino). }\end{array}$ & $\begin{array}{l}\text { Percentual de } \\
\text { estudantes do } \\
\text { sexo feminino }\end{array}$ \\
\hline Reprovação & Categórica & $\begin{array}{l}\text { Q45: “Você já foi reprovado?" (A) Sim, } \\
\text { (B) Sim, uma vez e (C) Sim, duas } \\
\text { vezes ou mais). }\end{array}$ & $\begin{array}{l}\text { Percentual de } \\
\text { estudantes com ao } \\
\text { menos uma } \\
\text { reprovação }\end{array}$ \\
\hline NSE & Contínua & $\begin{array}{l}\text { O NSE é calculado a partir da } \\
\text { escolaridade dos pais, da posse de } \\
\text { bens e da contratação de serviços } \\
\text { domésticos pela família dos alunos. } \\
\text { Com base nesses dados, empregamos } \\
\text { a Teoria da Resposta ao Item. Neste } \\
\text { trabalho o NSE foi dividido em quartis. }\end{array}$ & $\begin{array}{l}\text { Percentual de } \\
\text { estudantes com } \\
\text { baixo NSE (1º } \\
\text { quartil) }\end{array}$ \\
\hline
\end{tabular}




\begin{tabular}{|l|l|l|l|}
\hline & $\begin{array}{l}\text { Os níveis de aprendizado foram } \\
\text { descritos de acordo com os níveis de } \\
\text { proficiência elaborados por Soares } \\
\text { (2009), para descrever o aprendizado } \\
\text { dos alunos a partir da pontuação } \\
\text { obtida por eles na escala de } \\
\text { proficiência do Saeb. }\end{array}$ & $\begin{array}{l}\text { Percentual de } \\
\text { estudantes com } \\
\text { desempenho } \\
\text { abaixo do básico } \\
\text { em Leitura }\end{array}$ \\
& Contínua & $\begin{array}{l}\text { Abaixo do básico: }(\leq 150 \text { Leitura } \mid \leq 175 \\
\text { Matemática), Básico: ( } \geq 150 \text { a 200 } \\
\text { Leitura } \mid \geq 175 \text { a 200 Matemática), } \\
\text { Adequado: ( } \geq 200 \text { a 250 Leitura } \mid \geq 200 \\
\text { a 225 Matemática) e Avançado: }(>200 \\
\text { Leitura } \mid>225 \text { Matemática). }\end{array}$ & $\begin{array}{l}\text { Percentual de } \\
\text { estudantes com } \\
\text { desempenho } \\
\text { abaixo do básico } \\
\text { em Matemática }\end{array}$ \\
\hline
\end{tabular}

Fonte: autoras.

A escolha das variáveis foi orientada pela literatura educacional e sociológica, correspondendo aos perfis que apresentam desvantagens escolares (Couri, 2010; Alves et al., 2016; Ribeiro, 2018). Considerando essas categorias calculamos o percentual de cada uma delas ao nível das turmas em cada escola. Assim, obtivemos o percentual de alunos autodeclarados pretos e pardos, de meninas, de estudantes reprovados uma vez ou mais, o percentual de estudantes no $1^{\circ}$ quartil de NSE e com aprendizado em Leitura e Matemática abaixo do básico.

A próxima fase consistiu em analisar o quanto a composição dessas turmas é diferente dentro de uma mesma escola e, nesse sentido, verificar o nível de disparidade entre os perfis sociodemográficos. Para realizar essa análise foi necessária a criação de uma medida de desigualdade.

\section{Desigualdades de composição entre turmas}

Definida a medida de composição social ou o modo como as turmas estavam organizadas tratou-se de mensurar, nas escolas, o grau de desigualdade em relação a essa distribuição. A solução escolhida foi a elaboração de uma medida sintética que possibilitasse avaliar o nível de disparidade na distribuição dos alunos entre as turmas, segundo as características socioeconômicas e escolares associadas a menos oportunidades de aprendizado. Dessa forma quanto maior a desigualdade em relação à composição maiores, nesta interpretação, as chances de lacuna de aprendizado nas escolas.

Aplicamos o Índice de Theil-L, uma medida estatística que avalia a concentração de uma dada variável quantitativa entre grupos (Theil,1967). Também chamado de índice de entropia generalizada, a medida informa sobre a redundância de uma dada variável entre grupos (Unesco, 2019). Em nosso caso os grupos são as turmas de uma escola e os dados a sua composição: percentual de estudantes pretos, pardos, com reprovação, com baixo NSE e baixo desempenho em Leitura e Matemática. Como ilustração, o Índice de Theil-L assume que, para cada uma das características de composição observadas, 
escolas em que todas as turmas possuem o mesmo percentual de estudantes em cada categoria são aquelas com total redundância de composição e, portanto, onde não há disparidade em relação àquele aspecto. Quanto maiores as diferenças entre os percentuais observados nas turmas, maior a desigualdade.

Matematicamente o Índice de Theil-L é operacionalizado a partir do cálculo das médias aritmética $(\mu)$ e geométrica $(\tilde{\mu})$ de um ativo ou variável $y_{i}$ entre grupos representados por $n$ e onde $l n$ é o logaritmo natural da razão entre as médias:

$$
\begin{aligned}
& \text { Theil-L=1/n } \sum \ln 1 /\left(\mathrm{n} y_{i}\right) \\
& =\ln \mu / \tilde{\mu}
\end{aligned}
$$

O índice apresenta características positivas em relação a outras medidas de desigualdade, porque não sofre grandes variações em função do tamanho da população. Ele também utiliza todos os pontos da distribuição e necessita de poucas informações sendo, portanto, fácil de implementar computacionalmente (Unesco, 2019). Além disso a sua versão padronizada, que foi utilizada aqui, possui uma interpretação bem intuitiva com variação entre 0 e 1.

A padronização é dada pela divisão de toda a equação pelo logaritmo natural $(l n)$ do tamanho da população, o que pode ser expresso por meio da aplicação de sua operação inversa, o exponencial, conforme a expressão a seguir:

$$
\text { Theil-L Padronizado=1- } \exp (-(\ln \mu / \tilde{\mu}))
$$

Para que fique mais claro o modo como o indicador foi utilizado neste exercício a tabela 1 apresenta o processo de elaboração do Índice de Theil-L para três escolas hipotéticas com um total de 100 alunos matriculados no $5^{\circ}$ ano do ensino fundamental e distribuídos em duas turmas, escolas 1 e 2, ou três turmas, escola 3. A análise consistirá em medir a desigualdade na distribuição de 50 estudantes pretos, classificados assim por meio de autodeclaração, compondo o percentual apresentado na coluna C.

\begin{tabular}{|c|c|c|c|c|c|c|c|c|}
\hline & & $\begin{array}{c}\text { (A) } \\
\text { Total de } \\
\text { Alunos }\end{array}$ & $\begin{array}{l}\text { (B) } \\
\text { Alunos } \\
\text { pretos }\end{array}$ & $\begin{array}{c}\text { (C) } \\
\text { Percentual } \\
\text { de alunos } \\
\text { pretos por } \\
\text { turma }\end{array}$ & $\begin{array}{c}\text { (D) } \\
\text { Média } \\
\text { Aritméti } \\
\text { ca }\end{array}$ & $\begin{array}{c}(\mathrm{E}) \\
\text { Média } \\
\text { Geométrica }\end{array}$ & $\begin{array}{c}(F) \\
\text { Theil-L }\end{array}$ & $\begin{array}{c}\text { (G) } \\
\text { Theil-L } \\
\text { padronizado }\end{array}$ \\
\hline \multirow{3}{*}{ Escola 1} & Total & 100 & 50 & $50 \%$ & \multirow{3}{*}{$50,0 \%$} & \multirow{3}{*}{$40,0 \%$} & \multirow{3}{*}{0,223} & \multirow{3}{*}{0,200} \\
\hline & Turma 1 & 50 & 40 & $80 \%$ & & & & \\
\hline & Turma 2 & 50 & 10 & $20 \%$ & & & & \\
\hline \multirow{3}{*}{ Escola 2} & Total & 100 & 50 & $50 \%$ & \multirow{3}{*}{$50,0 \%$} & \multirow{3}{*}{$50,0 \%$} & \multirow{3}{*}{0,000} & \multirow{3}{*}{0,000} \\
\hline & Turma 1 & 50 & 25 & $50 \%$ & & & & \\
\hline & Turma 2 & 50 & 25 & $50 \%$ & & & & \\
\hline \multirow{4}{*}{ Escola 3} & Total & 100 & 50 & $50,0 \%$ & \multirow{4}{*}{$49,8 \%$} & \multirow{4}{*}{$46,6 \%$} & \multirow{4}{*}{0,065} & \multirow{4}{*}{0,063} \\
\hline & Turma 1 & 34 & 25 & $73,5 \%$ & & & & \\
\hline & Turma 2 & 33 & 10 & $30,3 \%$ & & & & \\
\hline & Turma 3 & 33 & 15 & $45,5 \%$ & & & & \\
\hline
\end{tabular}

Tabela 1 -

Simulação do processo de construção do indicador de Theil-L.

Fonte: autoras. 
Todas as escolas possuem metade dos estudantes classificados como pretos, porém na escola 2 temos a situação de redundância ou igualdade total, ou seja, as duas turmas possuem o mesmo percentual de alunos com essa característica e, portanto, 0 índice padronizado de Theil-L é zero.

$\mathrm{Na}$ escola 1 verificamos a situação mais extrema de desigualdade entre as três simuladas. Nela uma turma responde por $80 \%$ do total de alunos pretos na escola, alcançando um valor de 0,2 na escala padronizada de Theil-L. A escola 3 aparece em situação intermediária, em que existe desigualdade, porém, há menor concentração dentro das turmas do que ocorre na primeira (Theil-L padronizado $=0,063$ ).

Duas decisões para o cálculo do índice foram tomadas. A primeira consistiu em analisar as escolas com no mínimo duas turmas. A segunda diz respeito às informações presentes no banco de dados de turmas. A média geométrica envolve o produto das variáveis, por isso ela não é calculada quando há valores nulos. Por consequência, em escolas em que ao menos uma turma não apresentasse alunos numa das situações avaliadas na medida de composição, para que ainda assim a escola pudesse participar do estudo, a turma recebeu o valor de $0,01 \%$. Esse valor foi escolhido arbitrariamente, dado que é muito próximo a zero, tornando possível que a turma integrasse a análise e o cálculo da média geométrica fosse viabilizado.

$\mathrm{Na}$ sequência, apresentaremos os resultados do índice de Theil-L calculados para as escolas brasileiras de maneira a verificar a sua significância estatística, ou seja, em que medida é possível assumir que existe desigualdade entre turmas nas escolas observadas e para quais características ela assume valores ais elevados.

Feito isso, com vistas a testar a nossa última hipótese, por meio de uma análise de variância, verificaremos se essa diferença varia em função dos critérios de organização das turmas informados pelos diretores.

O diretor de cada escola participante da Prova Brasil responde a um questionário específico acerca do seu perfil social e econômico, sobre a formação pessoal e sobre a escola em que atua. A pergunta utilizada nesta etapa da pesquisa foi: "neste ano, qual foi o principal critério utilizado para a formação das turmas nesta escola?" As opções de resposta são: 1- Homogeneidade quanto à idade (alunos com a mesma idade); 2Homogeneidade quanto ao rendimento escolar (alunos com rendimento similar); 3Heterogeneidade quanto à idade (alunos com idades diferentes); 4- Heterogeneidade quanto ao rendimento escolar (alunos com rendimentos diferentes); 5- Outro critério; 6Não houve critério.

\section{Resultados}

A distribuição dos alunos entre as turmas a partir das medidas de composição, baseadas nos perfis sociodemográficos e escolares dos estudantes, demonstra a existência de grande variação entre as turmas no país. Observando os valores mínimo e máximo das medidas de composição percebemos que, para todos os perfis de estudantes, existem, ao mesmo tempo, turmas com quase nenhum aluno e outras com quase $100 \%$ dos estudantes em cada medida de composição escolhida. 
Tabela 2 -

Descrição da média de composição das turmas por perfis sociodemográficos e escolares- Rede Pública - 5a ano.

\begin{tabular}{c|c|c|c|c|c|c|c}
\hline & $\begin{array}{c}\text { Percentual de } \\
\text { pretos }\end{array}$ & $\begin{array}{c}\text { Percentual de } \\
\text { pardos }\end{array}$ & $\begin{array}{c}\text { Percentual de } \\
\text { meninas } \\
\text { alunos } \\
\text { reprovados }\end{array}$ & $\begin{array}{c}\text { Percentual de } \\
\text { Percentual } \\
\text { de alunos } \\
\text { no quartil } \\
\text { de NSE }\end{array}$ & $\begin{array}{c}\text { Percentual de } \\
\text { alunos com } \\
\text { desempenho } \\
\text { abaixo do } \\
\text { básico } \\
\text { em Leitura } \\
\text { de alunos } \\
\text { com } \\
\text { desempenh } \\
\text { o abaixo do } \\
\text { básico em } \\
\text { Matemática }\end{array}$ \\
\hline N & 97.772 & 97.772 & 97.772 & 97.772 & 97.772 & 97.772 & 97.772 \\
\hline Mínimo & 0,01 & 0,01 & 0,01 & 0,01 & 0,01 & 0,01 & 0,01 \\
\hline Máximo & 100,00 & 100,00 & 100,00 & 100,00 & 100,00 & 100,00 & 100,00 \\
\hline Média & 10,80 & 43,66 & 48,93 & 23,24 & 26,09 & 13,18 & 20,03 \\
\hline $\begin{array}{c}\text { Desvio } \\
\text { Padrão }\end{array}$ & 10,21 & 20,18 & 12,12 & 17,59 & 21,37 & 15,00 & 18,77 \\
\hline Fonte: & & & & & &
\end{tabular}

Fonte: autoras com dados da Prova Brasil de 2017.

Ainda que a medida de composição seja aplicada como indicadora do contexto social e escolar das turmas e estabelecimentos de ensino nas modelagens estatísticas, elas não explicitam, apropriadamente, se há concentração de alunos com determinado perfil em certas turmas de uma mesma escola, ou seja, se há desigualdade de composição entre as turmas. Para verificarmos a variação da composição utilizamos o Índice de Theil- L, gráfico 1. Com o uso desse índice podemos examinar se a maneira como os estudantes estão organizados em turmas é mais desigual em algumas escolas do que em outras.

Na tabela 2 apresentamos a distribuição dos perfis escolares e sociodemográficos, tendo como unidade de análise as turmas $(\mathrm{N}=97.772)$, porém, no gráfico 1 , a unidade de análise é a escola $(N=27.491)$ e nele verificamos as diferenças de concentração de perfis entre as turmas. Dessa maneira, o gráfico 1 apresenta a média do Índice de Theil-L para todas as escolas e o intervalo de confiança da medida.

Gráfico 1 -

Índice de Theil-L e descrição da desigualdade de composição da rede pública - 5o ano.

Theil- L Preto

Theil-L Leitura abaixo do básico

Theil-L Matemática abaixo do básico

Theil L Reprovação

Theil-L NSE $1^{\circ}$ quartil

Theil-L Pardo

Theil-L Meninas
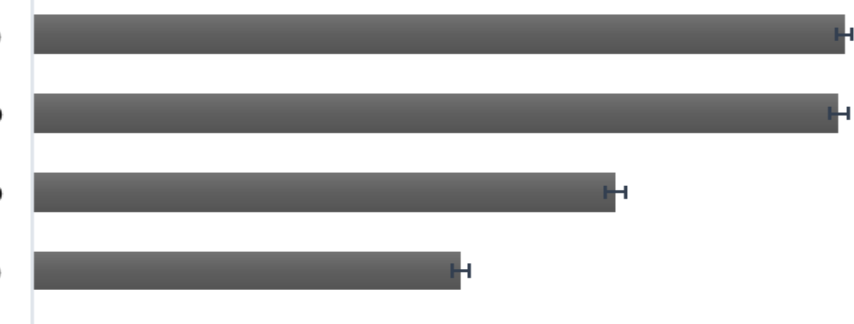

$$
\begin{array}{lllllllll}
0,00 & 0,05 & 0,10 & 0,15 & 0,20 & 0,25 & 0,30 & 0,35 & 0,40
\end{array}
$$

Fonte: autoras com dados da Prova Brasil 2017. 
Como explicitado na tabela 1 o Índice de Theil-L varia entre 0 e 1, sendo que valores mais próximos de 1 indicam mais desigualdade, enquanto os mais próximos de 0 demonstram mais igualdade. $O$ gráfico 1 sugere maior desigualdade em relação à presença de estudantes declarados pretos - média do índice igual a 0,35 - nas turmas do que em relação aos alunos pardos, cujo Índice de Theil é bem menor $(0,10)$.

Isto quer dizer que, em média, há mais concentração de turmas com alunos declarados pretos e uma maior homogeneidade na distribuição dos estudantes declarados pardos. Ou seja, além de estarem presentes em menor proporção, devido também à composição racial do país, os alunos pretos tendem a se concentrarem em poucas turmas e não estarem mais distribuídos entre todas as classes da escola.

Vale dizer que tão elevada quanto a desigualdade da presença de estudantes pretos é a concentração de alunos com desempenho abaixo do básico, principalmente, em Leitura. $O$ índice de Theil-L para o percentual de alunos com baixo desempenho em Matemática também é alto e aparece como o terceiro maior indicador dentre os perfis analisados neste estudo.

Descrevendo os critérios de organização dos estudantes nas turmas, segundo a declaração dos diretores, e o modo como o nosso indicador de desigualdades está distribuído em cada um deles, constatamos o descompasso entre a distribuição observada e a alegada pelo gestor.

Os critérios de alocação dos alunos às turmas podem seguir diferentes parâmetros, conforme as respostas dos diretores: tabela 4. Dentre eles são mais frequentes o critério de homogeneidade quanto à idade $-31,7 \%$ das escolas - e o de heterogeneidade quanto ao rendimento: $20 \%$ das escolas. Além disso é importante apontar que $21,5 \%$ das escolas adotaram outro critério e que $16,4 \%$ não adotaram nenhum critério de alocação dos estudantes. Mas esses critérios declarados pelos diretores coincidem com as diferenças de composição entre as turmas? O conjunto de gráficos de 2 a 8 ajuda a responder essa pergunta, apontando se a desigualdade entre turmas, expressa pelo Índice de Theil-L, em cada condição sociodemográfica ou escolar é diferente conforme os critérios de alocação de turmas.

Tabela 4 -

Descrição da declaração dos diretores quanto aos critérios utilizados na escola para a alocação dos alunos às turmas da rede pública - $5^{\circ}$ ano.

\begin{tabular}{l|c}
\hline $\begin{array}{l}\text { Homogeneidade quanto à idade: alunos com a mesma } \\
\text { idade }\end{array}$ & $31,7 \%$ \\
\hline Outro critério & $21,5 \%$ \\
\hline $\begin{array}{l}\text { Heterogeneidade quanto ao rendimento escolar: alunos } \\
\text { com rendimentos diferentes }\end{array}$ & $20,0 \%$ \\
\hline Não houve critério & $16,4 \%$ \\
\hline $\begin{array}{l}\text { Heterogeneidade quanto à idade: alunos com idades } \\
\text { diferentes }\end{array}$ & $5,3 \%$ \\
\hline $\begin{array}{l}\text { Homogeneidade quanto ao rendimento escolar: alunos } \\
\text { com rendimento similar }\end{array}$ & $5,1 \%$ \\
\hline
\end{tabular}

Fonte: autoras com dados da Prova Brasil 2017. 
Nos gráficos de 2 a 5 apresentamos a desigualdade da composição sociodemográfica das turmas e o critério de organização informado pelo diretor. Cada linha do gráfico representa a média da desigualdade para cada um dos critérios e o seu intervalo de confiança é de $95 \%$. Se os intervalos se sobrepõem, ou seja, se eles apresentam valores em comum, não é possível assumir que as médias são diferentes. No caso do gráfico 2, para o percentual de estudantes da raça/cor preta, todos os intervalos estão sobrepostos, exceto os de heterogeneidade quanto ao rendimento escolar. Isso sugere que apenas nas escolas em que o diretor afirmou ter utilizado esse critério heterogeneidade quanto ao rendimento - foi possível identificar maior desigualdade entre turmas quanto à composição por cor/raça preta.

O resultado aponta a contradição entre a alegada heterogeneidade - condição ideal de composição - e a homogeneidade dentro das turmas apontada pelo índice de Theil-L. Observe que os maiores valores do índice de desigualdade indicam que há mais turmas homogêneas quanto à presença de estudantes declarados pretos, em outras palavras, algumas turmas com poucos e outras com muitos alunos com esse perfil. Esse primeiro gráfico não permite uma avaliação completa da relação entre raça e desempenho, porém o esperado seria que os maiores níveis de desigualdade para qualquer tipo de perfil sociodemográfico ou escolar fosse encontrado em escolas em que os diretores afirmassem utilizar critérios de homogeneidade e não o contrário.

Gráfico 2 - Índice de Theil-L - pretos - por critério de organização das turmas informado pelos diretores - 5 ano

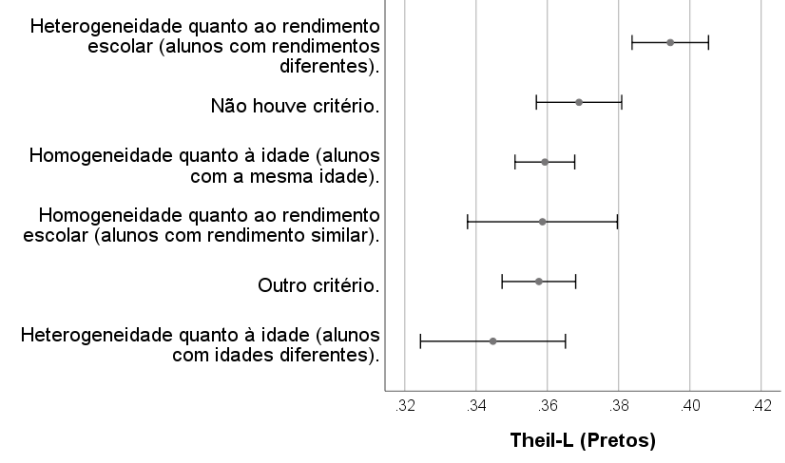

Fonte: autoras com dados da Prova Brasil, 2017.
Gráfico 3 - Índice de Theil-L - pardos - por critério de organização das turmas informado pelos diretores - 5 ano

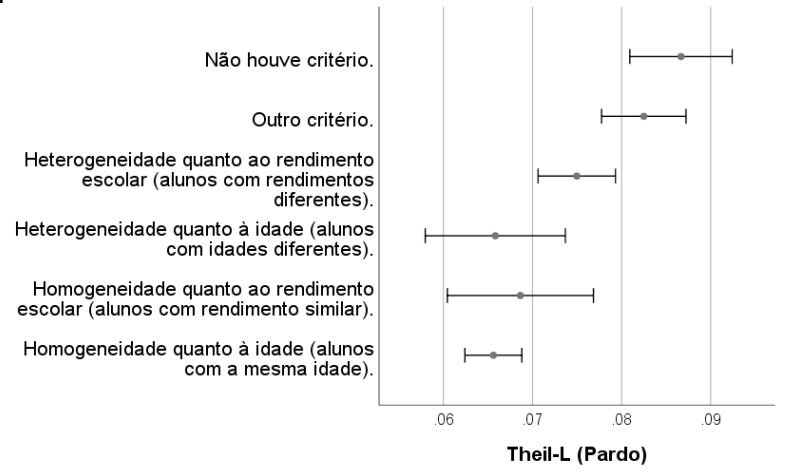

Fonte: autoras com dados da Prova Brasil, 2017.

Em contrapartida, no gráfico 3 , quando analisamos as desigualdades quanto à composição de cor/raça parda, as médias não são muito distintas entre os diferentes critérios adotados pelos estabelecimentos para a formação das turmas. Entretanto, as escolas que informaram adotar, novamente, o critério de heterogeneidade quanto ao rendimento, mas que também informaram seguir algum outro critério ou ainda não utilizar quaisquer critérios de alocação de estudantes são mais desiguais do que escolas que adotam homogeneidade quanto à idade.

É interessante notar que o critério informado de organização das turmas pelos diretores está associado de maneiras diversas aos perfis sociodemográficos. Podemos observar que, ao contrário do que acontece com os estudantes negros - pretos e pardos -, a desigualdade quanto à composição por sexo - meninas gráfico 4 -, que apresenta o 
menor valor médio do Índice de Theil-L, gráfico 1, é menor quando a escola relata adotar o critério de heterogeneidade quanto ao rendimento. Para esse grupo o descompasso entre o critério informado e a prática de enturmação não se apresenta, gráfico 4.

Gráfico 4 - Índice de Theil-L - meninas - por critério de organização das turmas informado pelos diretores - $5^{\circ}$ ano

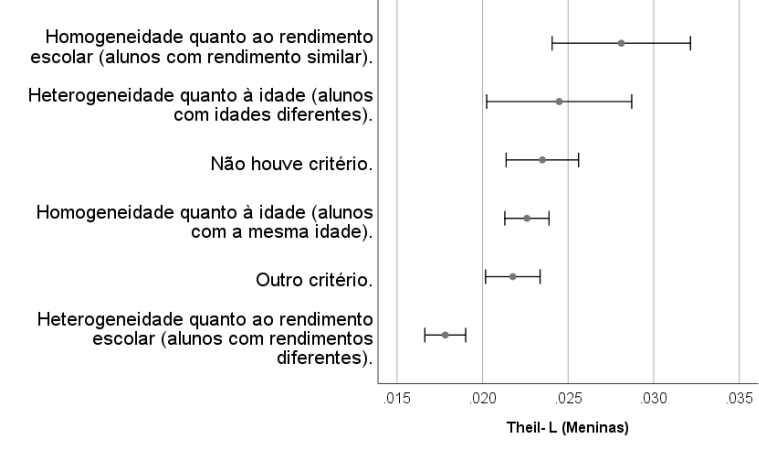

Fonte: autoras com dados da Prova Brasil, 2017.
Gráfico 5 - Índice de Theil-L -NSE 1ำ quartil por critério de organização das turmas informado pelos diretores - $5^{\circ}$ ano

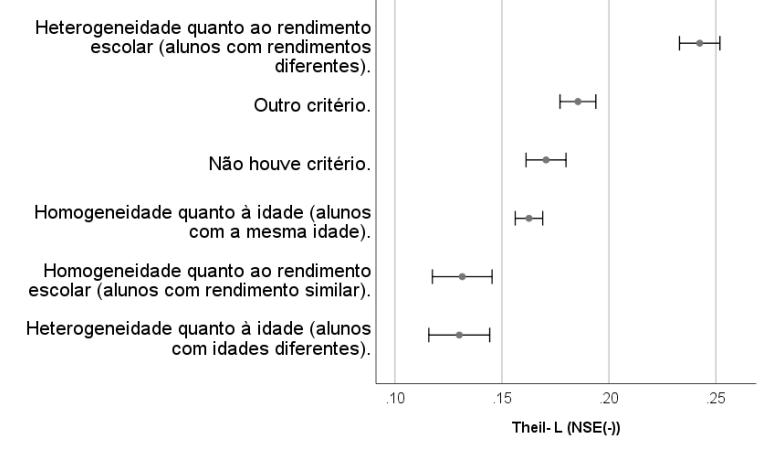

Fonte: autoras com dados da Prova Brasil, 2017.

Mais uma vez, de forma não esperada, os resultados do gráfico 5 revelaram que estabelecimentos escolares que afirmam adotar o critério de heterogeneidade quanto ao rendimento possuem mais concentração de alunos com baixo NSE. Em outras palavras, escolas cujo diretor informa que as turmas são formadas de modo a manter mais diversidade em relação ao desempenho são aquelas na qual há turmas mais homogêneas quanto ao nível socioeconômico dos estudantes, o que representa maior desigualdade.

O gráfico 6 apresenta as médias das desigualdades entre a composição das turmas quanto ao percentual de reprovados. Os resultados mostram que escolas que adotam 0 critério de heterogeneidade quanto ao rendimento se destacam como as mais desiguais.

A reprovação é um tema debatido na literatura educacional, tanto em suas implicações no campo da política educacional, quanto para escola e os estudantes (Glória, 2004; Gil, 2018; Ribeiro, 2018). Há uma crença por parte do corpo docente e dos pais de que o aluno reprovado tem mais tempo e possibilidades de aprendizado, porém não é o que acontece na prática (De Cassia; Lima, 2007; Jacomini, 2010; Ribeiro, 2018).

Os resultados descritos no gráfico 6 devem ser analisados com parcimônia, uma vez que o uso do índice não permite uma análise mais apurada das estratégias pedagógicas que possam levar a tal efeito. As pesquisas sobre reprovação ressaltam a importância de uma reformulação das estratégias e práticas pedagógicas, com uma perspectiva menos seletiva, na medida em que a reprovação mais exclui do que favorece ao aprendizado (Glória, 2004; Correa; Bonamino; Soares, 2014; Almeida; Alves, 2020). 
Gráfico 6 -

Índice de Theil-L - reprovados - por critério de organização das turmas informado pelos diretores $-5^{\circ}$ ano.

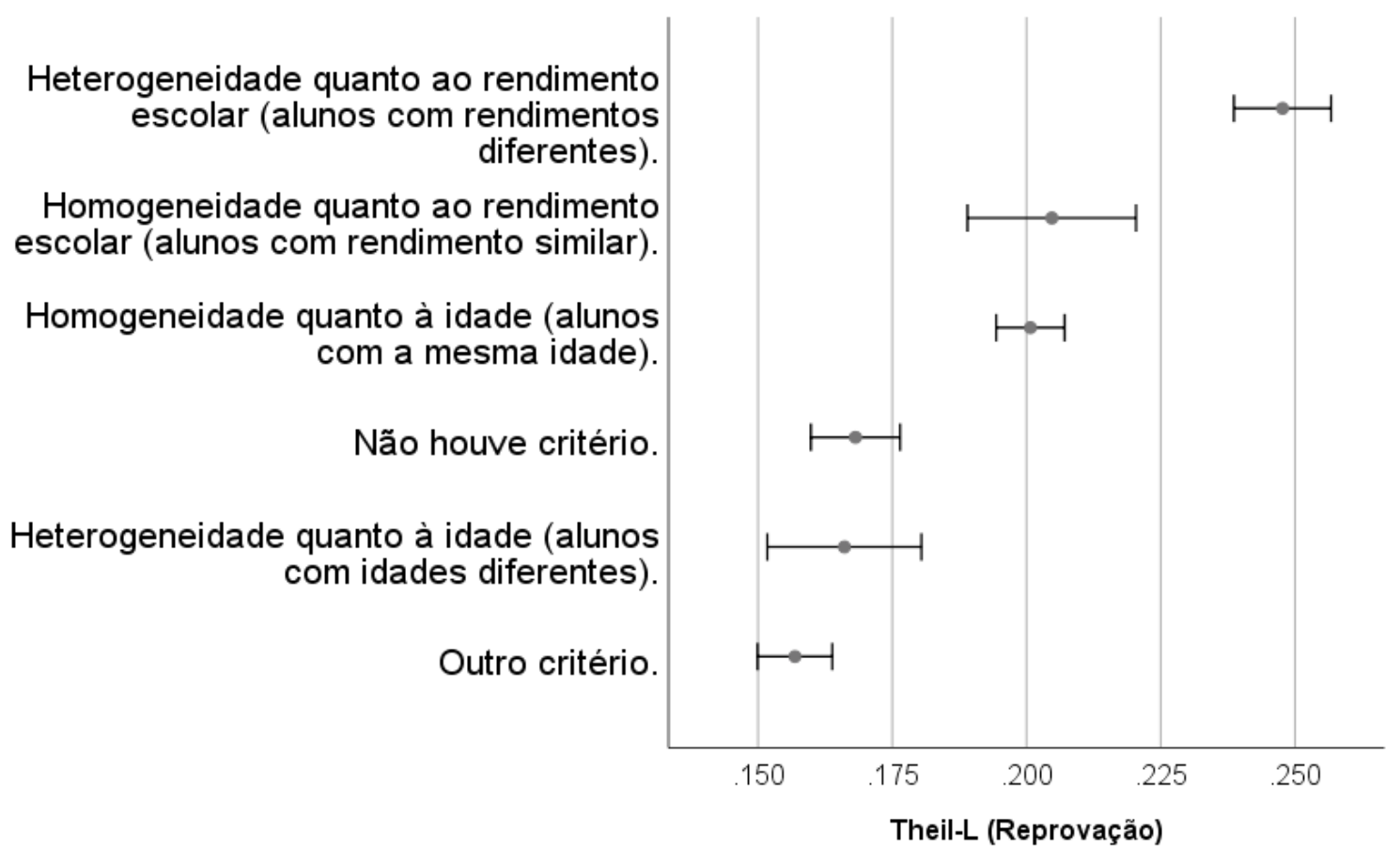

Fonte: autoras com dados da Prova Brasil, 2017.

Por fim os gráficos 7 e 8 apresentam os resultados encontrados para desigualdade de desempenho entre turmas com maior número de alunos com proficiência abaixo do básico, respectivamente, em Leitura e Matemática. Constatamos que, em ambos os gráficos, as maiores desigualdades entre turmas quanto à composição por desempenho ocorrem nas escolas que informaram adotar o critério de heterogeneidade quanto ao rendimento. O critério de heterogeneidade quanto à idade, por sua vez, está associado a menores desigualdades.

Gráfico 7 - Índice de Theil-L - abaixo do básico Leitura - por critério de organização das turmas informado pelos diretores - $5^{\circ}$ ano

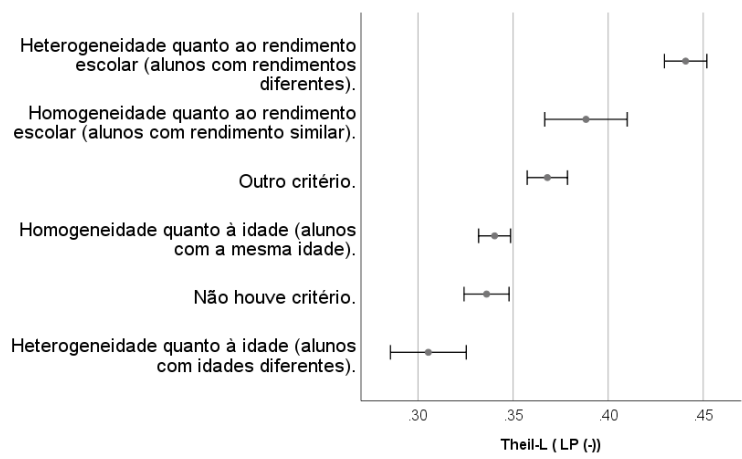

Fonte: autoras com dados da Prova Brasil, 2017.
Gráfico 8 - Índice de Theil-L - abaixo do básico Matemática - por critério de organização das turmas informado pelos diretores - 5ำ ano

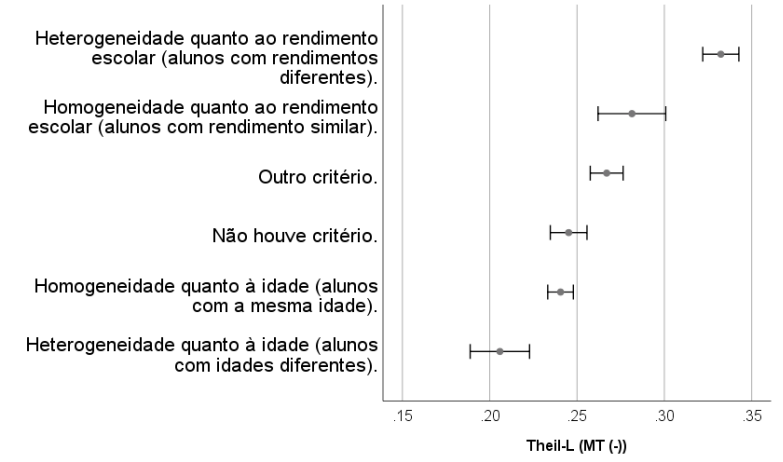

Fonte: autoras com dados da Prova Brasil, 2017. 
Aqui, justamente, é o rendimento que está em questão e novamente não observamos correspondência com o que poderíamos esperar, segundo a literatura revisada acima, isto é, uma situação mais favorável, de menor desigualdade, nas escolas em que os diretores afirmaram garantir a heterogeneidade das turmas. Podemos dizer que a homogeneidade das turmas provoca menos desigualdades de desempenho? Certamente não, porque não se trata de um estudo experimental. O que podemos dizer é que não há a correspondência esperada entre os critérios informados e a medida nesse quesito de composição social, de desempenho e de reprovação.

Os motivos para tais resultados não são possíveis de serem apontados de forma definitiva neste trabalho. Há hipóteses de natureza substantiva, relacionadas ao modo de organização das escolas, e às formas como as desigualdades se revelam por meio de outros atributos, como os de natureza demográfica, que não são cobertos pelos critérios apontados aqui.

Poderíamos levantar ainda questionamentos acerca do sentido atribuído pelos diretores a uma questão estruturada como esta. Aspectos como o embaraço e a expectativa de oferecer respostas corretas em um instrumento de coleta de dados administrativo podem contribuir para que as informações revelem apenas parcialmente 0 modo como se dão os critérios de alocação de estudantes entre turmas.

Como não é possível, neste exercício, controlar tais variáveis, apontamos como principal contribuição deste trabalho a reflexão sobre as formas de medir a desigualdade intraescolar, observando o modo como ela varia entre os diferentes tipos de marcadores de desvantagem social observados e quais os ganhos do trabalho com medidas síntese, como a do índice de Theil-L.

\section{Considerações finais}

Nesta pesquisa teve-se como principal objetivo investigar as desigualdades de composição entre turmas, examinando alguns perfis sociodemográficos de alunos e correlacioná-los aos critérios de organização das turmas informados pelos diretores das escolas de $5^{\circ}$ ano do ensino fundamental das redes municipais e estaduais de todo Brasil.

Os resultados iniciais revelaram, principalmente, que os estudantes com baixo desempenho escolar tendem a ser alocados numa mesma turma e isto também ocorre com alunos da cor preta. Uma consequência da composição das turmas refere-se ao efeito de pares, pois, se um aluno de uma mesma turma pode estimular o outro para o aprendizado, isto se torna mais difícil quando há numa turma, por exemplo, muitos estudantes com desempenho em Leitura abaixo do esperado. O desejado é que haja maiores chances de aprendizado em classes, nas quais alunos com diferentes níveis de desempenho estejam em contato.

Isto posto é significativo analisar que nenhuma escola vai compor suas turmas deliberadamente a partir de critérios raciais ou socioeconômicos. Porém, outros critérios objetivos, como o desempenho e a reprovação, podem impor um viés importante ao processo de enturmação nas escolas. Estão criadas aí as condições para uma sobreposição de desigualdades escolares. É possível que seja essa interseccionalidade uma explicação plausível para os resultados contraditórios observados quando analisamos a medida de desigualdade intraescolar em relação aos critérios apontados pelos gestores escolares (Dubet, 2001; Alves; Soares; Xavier, 2016).

\begin{tabular}{|l|l|l|l|l|l|}
\hline Regae: Rev. Gest. Aval. Educ. & Santa Maria & v. 10 & n. 19 & e65270, p. 1-19 & 2021
\end{tabular}


Com isso são abertas possibilidades para pesquisas futuras. A análise de outra etapa/ano, como o 9 ano, por exemplo, pode informar resultados mais desafiadores, considerando a sua tendência a maior desigualdade de desempenho e maiores níveis de abandono. Uma hipótese é de que os perfis podem ser similares ao do $5^{\circ}$ ano, porém será que eles tendem a estar mais desigualmente distribuídos entre as turmas? São bemvindas pesquisas de campo para que fatores pedagógicos sejam investigados, a fim de que se entenda essa questão. Além disso os critérios descritos como 'não houve critério' ou 'outro critério' não deixam uma clara interpretação para os resultados. Isto dificulta os resultados para estudantes pardos, pois as turmas formadas, de acordo com estes critérios de difícil interpretação, influenciam o desempenho desses alunos.

Dessa maneira, pesquisas com essa temática tornam-se importantes, visto que a forma de organização e composição das turmas dentro da escola pode funcionar como uma maneira de equalizar o aprendizado e mitigar ou reforçar as desigualdades escolares.

\section{Referências}

ALMEIDA, Frederico Alves; ALVES, Maria Teresa Gonzaga. A cultura da reprovação em escolas organizadas por ciclos. Revista Brasileira de Educação, Belo Horizonte, v. 26, 2021, p. 1-28.

ALVES, Maria Teresa Gonzaga; SOARES, José Francisco. Efeito-escola e estratificação escolar: o impacto da composição de turmas por nível de habilidade dos alunos. Educação em Revista, Belo Horizonte, n. 45, 2007, p. 25-59.

ALVES, Maria Teresa Gonzaga; FRANCO, Creso. A pesquisa em eficácia escolar no Brasil: evidências sobre o efeito das escolas e fatores associados à eficácia escolar. In: BROOKE, Nigel; SOARES, José Francisco (org.). Pesquisa em eficácia escolar: origem e trajetórias. Belo Horizonte: UFMG, 2008, p. 482-500.

ALVES, Maria Teresa Gonzaga; SOARES, José Francisco. Contexto escolar e indicadores educacionais: condições desiguais para a efetivação de uma política de avaliação educacional. Educação e Pesquisa, Belo Horizonte, v. 39, n. 1, 2013, p. 177194.

ALVES, Maria Teresa; SOARES, José Francisco; XAVIER, Flavia Pereira. Desigualdades educacionais no ensino fundamental de 2005 a 2013: hiato entre grupos sociais. Belo Horizonte Revista Brasileira de Sociologia, Belo Horizonte, v. 4, n. 7, 2016, p. 49-82.

BARBOSA, Maria Eugénia. Ferrão; FERNANDES, Cristiano. A escola brasileira faz diferença? Uma investigação dos efeitos da escola na proficiência em Matemática dos alunos da 4⿳亠丷厂 série. In: FRANCO, Creso (org.). Promoção, ciclos e avaliação educacional, Porto Alegre, 2001, p. 155-172.

BARBOZA, Eleuza Maria Rodrigues. A composição das turmas e o desempenho escolar na rede pública de ensino de Minas Gerais. Rio de Janeiro: PUCRJ, 2006. 110f. Tese (Doutorado em Educação). Pontifícia Universidade Católica do Rio de Janeiro.

BARTHOLO, Tiago Lisboa; COSTA, Marcio da. Turnos e segregação escolar: discutindo as desigualdades intraescolares. São Paulo, Cadernos de Pesquisa, São Paulo, v. 44, n. 153, 2014, p. 670-692.

BRASIL. Lei n. 9.394/96, de 20 de dezembro de 1996: estabelece as diretrizes e bases da Educação Nacional. Brasília: Senado Federal, 1996. 
BRASIL. Plano nacional da educação,. Brasília: MEC, 2001.

COLEMAN, James S, et al. Equality of educational opportunity. Washington: [s.n.], 1966.

CORREA, Erisson Viana; BONAMINO, Alicia; SOARES, Tufi Machado. Evidências do efeito da repetência nos primeiros anos escolares. Estudos em Avaliação Educacional, São Paulo, v. 25, n. 59, 2014, p. 242-269.

COURI, Cristina. Nível socioeconômico e cor/raça em pesquisas sobre efeito escola. Estudos em Avaliação Educacional, São Paulo, v. 21, n. 47, 2010, p. 449-472.

DA COSTA, Marcio; KOSLINSKI, Mariane C. Prestígio escolar e composição de turmas explorando a hierarquia em redes escolares. Estudos em Avaliação Educacional, São Paulo, v. 19, n. 40, 2008, p. $305-330$.

DE CÁSSIA PETRENAS, Rita; LIMA, Rita de Cássia Pereira. Ciclos de aprendizagem e reprovação escolar: reflexões sobre representações sociais de professores. Práxis Educativa, Ponta Grossa, v. 2, n. 2, 2007, p. 161-168.

DUBET, François. As desigualdades multiplicadas. Revista Brasileira de Educação, São Paulo, n. 17, 2001, p. 5-18, 2001.

DUBET, François. Onde estariam as promessas de mudança no sistema escolar. Belo Horizonte Presença Pedagógica, Belo Horizonte, v. 10, n. 59, 2004, p. 49-52.

DUBET, François. Desigualdades educacionais: estruturas, processos e modelos de justiça. $O$ debate ao longo dos últimos cinquenta anos na França. Jornal de Políticas Educacionais, Paraná, v. 13, n. 46, 2019, p. 1-28.

DUBET, François; DURU-BELLAT, Marie; VÉRÉTOUT, Antoine. As desigualdades escolares antes e depois da escola: organização escolar e influência dos diplomas. Sociologias, Porto Alegre, v. 14, n. 29, 2012, p. 22-70.

DURU-BELLAT, Marie. Amplitude e aspectos peculiares das desigualdades sociais na escola francesa. Educação e Pesquisa, São Paulo, v. 31, n. 1, 2005, p. 13-30.

FRANCO, Creso, et al. Qualidade e equidade em educação: reconsiderando o significado de fatores intra-escolares. Rio de Janeiro. Ensaio: Avaliação e Políticas Públicas em Educação, Rio de Janeiro, v. 15, n. 55, 2007, p. 277-298.

GLÓRIA, Dília Maria Andrade; MAFRA, Leila de Alvarenga. A prática da não-retenção escolar na narrativa de professores do ensino fundamental: dificuldades e avanços na busca do sucesso escolar. Educação e Pesquisa, São Paulo, v. 30, n. 2, 2004, p. 231250.

GIL, Natália de Lacerda. Reprovação escolar no Brasil: história da configuração de um problema político-educacional. Revista Brasileira de Educação, Rio de Janeiro, v. 23, 2018, p. 1-23.

GOMES, Candido Alberto. A escola de qualidade para todos: Abrindo as camadas da Cebola. Ensaio: Avaliação e Políticas Públicas em Educação, Rio de Janeiro, n. 48, 2005, p. 281-306.

JACOMINI, Márcia Aparecida. Por que a maioria dos pais e alunos defende a reprovação? Cadernos de Pesquisa, São Paulo, v. 40, n. 141, 2010, p. 895-919.

KLEIN, Ruben. Utilização da teoria de resposta ao item no sistema nacional de avaliação da educação básica - Saeb. In: BROOKE, Nígel; ALVES, Maria Teresa Gonzaga; OLIVIERA, Lina Kátia Mesquita de (ed.). A avaliação da educação básica: a experiência brasileira. Belo Horizonte: Fino Traço, 2015, p. 189-192. 
LEO, Elisabette Goncalves Cipriano; CRUZ, Tatiana Maria da. A formação de turmas e sua atribuição aos professores: possíveis influências na proficiência média em matemática dos alunos do $9^{\circ}$ ano na Prova Brasil. SEMINÁRIO DO GRUPO DE ESTUDOS E PESQUISA EM POLÍTICA EDUCACIONAL, 2, 2016. Anais ... Campinas: Gepale, 2016.

LEO, Elisabette Goncalves Cipriano; CRUZ, Tatiana Maria da. A composição das turmas por heterogeneidade escolar e sua relação com o aprendizado do aluno. REUNIÃO CIENTÍFICA REGIONAL SUDESTE DA ASSOCIAÇÃO NACIONAL DE PESQUISA EM EDUCAÇÃO, 13, 2018. Anais ... Campinas: Anped, 2018.

OLIVEIRA, Adolfo Samuel de. Progressão continuada e outros dispositivos escolares: êxito e fracasso escolar nos anos iniciais do ensino fundamental. São Paulo: USP, 2014. 435f. Tese (Doutorado em Educação) - Faculdade de Educação, Universidade de São Paulo, São Paulo.

PLOWDEN COMMITTE. Children and their primary scholl. London: HMSO,. 1967.

REYNOLDS, David; TEDDLIE, Charles. Os processos de eficácia escolar. In: BROOKE, Nigel; SOARES, José Francisco (org.). Pesquisa em eficácia escolar: origem e trajetórias. Belo Horizonte: UFMG, 2008, p. 297-328.

RIBEIRO, Vanda Mendes et al. Crenças de professores sobre reprovação escolar. Educação em Revista, Belo Horizonte, v. 34, 2018, p. 1-35.

RIBEIRO, Carlos Antonio Costa. Classe, raça e mobilidade social no Brasil. Dados, Rio de Janeiro, v. 49, n. 4, 2006, p. 833-873.

SAMMONS, Pam. et al. Key characteristics of effective schools: aA review of school effectiveness research. $B$ \& MBC Distribution Services, 9 Headlands Business Park, Ringwood, Hants BH24 3PB, England, United Kingdom, 1995.

SOARES, José Francisco. O efeito da escola no desempenho cognitivo de seus alunos. REICE: Revista Iberoamericana sobre Calidad, Eficacia y Cambio en Educación, Madrid, v. 2, n. 2, 2004, p. 83-104.

SOARES, José Francisco. Melhoria do desempenho cognitivo dos alunos do ensino fundamental. Cadernos de Pesquisa, São Paulo, v. 37, n. 130, 2007, p. 135-160.

SOARES, José Francisco. Índice de desenvolvimento da educação de São Paulo: Idesp. Perspectiva, São Paulo, v. 23, n. 1, 2009, p. 29-41.

THEIL, Henry. Economics and information theory. Chicago: Rand McNally, 1967.

UNESCO. Manual para a medição da equidade na educação. Brasília: ONU, 2019.

Tatiana Maria Cruz é estudante no curso de Mestrado em Educação da Universidade Federal de Minas Gerais.

Endereço: Avenida Antônio Carlos, 6627 - 31270-901 - Belo Horizonte - MG -

Brasil.

Orcid: https://orcid.org/0000-0003-0939-3720.

E-mail: taticruz2813@ufmg.br. 
Flavia Pereira Xavier é professora na Faculdade de Educação da Universidade Federal de Minas Gerais.

Endereço: Avenida Antônio Carlos, 6627 - 31270-901 - Belo Horizonte - MG Brasil.

Orcid: https://orcid.org/0000-0002-8609-2756 .

E-mail: flaviapx@ufmg.br.

Valéria Cristina de Oliveira é professora na Faculdade de Educação da Universidade Federal de Minas Gerais.

Endereço: Avenida Antônio Carlos, 6627 - 31270-901 - Belo Horizonte - MG -

Brasil.

Orcid: http://orcid.org/0000-0002-2158-3191.

E-mail: valcrisoli@ufmg.br.

Critérios de autoria: os autores, coletivamente, participaram da concepção, execução, análise, interpretação e redação. Tatiana foi responsável pelo tratamento e pela análise dos dados. Flavia acompanhou e orientou o enquadramento teórico, o tratamento de dados, a elaboração da análise e a interpretação dos resultados. Valéria reelaborou as medidas de desigualdade de composição entre turmas e colaborou na revisão geral dos resultados.

Recebido em 14 de abril de 2021.

Aceito em 29 de julho de 2021.

(c) (i) $(9)$

(c) $\mathrm{BY}$ ND 